\title{
PEMANFAATAN MEDIA SOSIAL SEBAGAI ALTERNATIF DALAM MEMPERKENALKAN PRODUK PELAKU USAHA
}

\author{
Muhammad Sholeh', Suraya ${ }^{2}$, Anis Zaitunah'3 \\ 1,2 Program Studi Informatika, 3Program Studi Rekayasa Sistem Komputer \\ Institut Sains \& Teknologi AKPRIND, Jl. Kalisahak 28 Yogyakarta \\ E-mail 1'muhash@akprind.ac.id, 2suraya@akprind.ac.id, \\ 3aniszaitunah93@gmail.com
}

\begin{abstract}
Nowadays, social media has become one of the people's lifestyle, especially among young people. The existence of social media must be used by SMEs (small and medium enterprises) in marketing products. One of the social media that can be used is Instagram. Efforts to disseminate social media were made to representatives of UKM in Kasihan District. In this socialization, the focus of social media is Instagram. Based on the results of the questionnaire given to the socialization participants, $100 \%$ have used social media in marketing products and all respondents answered using WhatsApp as social media while 30\% used Instagram. The method of socialization is carried out by providing training and accompanying and providing an overview of the use of Instagram as a promotional media. Providing an overview of the use of Instagram was conveyed by speakers from business actors who have used Instagram as a promotional medium.
\end{abstract}

Keywords: UKM, social media, Instagram, promotion

\begin{abstract}
Abstrak
Media sosial di era teknologi saat ini menjadi salah satu trend gaya hidup masyarakat terutama kalangan anak muda. Keberadaan media sosial harus dapat digunakan pelaku UKM (usaha kecil menengah) dalam memasarkan produk. Salah satu media sosial yang dapat digunakan diantaranya adalah Instagram. Upaya untuk menyosialisasikan media sosial dilakukan pada perwakilan UKM yang ada di Kecamatan Kasihan. Media sosial yang menjadi topik pendampingan adalah Instagram. Berdasar hasil kuesioner yang diberikan pada peserta sosialisasi, $100 \%$ sudah menggunakan media sosial dalam memasarkan produk dan semua responden menjawab menggunakan WhatsApp sebagai media sosial sedangkan yang menggunakan Instagram $30 \%$. Metode pelaksanaan sosialisasi dilakukan dengan memberikan pelatihan dan mendampingkan serta memberikan gambaran penggunaan Instagram sebagai media promosi. Pemberian gambaran penggunaan Instagram disampaikan oleh narasumber dari pelaku usaha yang sudah menggunakan Instagram sebagai media promosi.
\end{abstract}

Kata Kunci: UKM, media sosial, Instagram, promosi 


\section{PENDAHULUAN}

Media sosial saat ini menjadi salah satu media yang dapat digunakan untuk sarana komunikasi. Penggunaan media yang berbasis sosial tidak hanya digunakan untuk komunikasi dalam penyampaian informasi tetapi dapat juga digunakan sebagai media promosi. Produk dari pelaku usaha dapat dipasarkan melalui media sosial, pelaku usaha dapat memasang foto dan narasi dari produk yang dibuat. Dengan cara ini, produk yang dipasang melalui media sosial diharapkan dibaca oleh pengguna media sosial. Keuntungan lain dari penggunaan media sosial sebagai media promosi adalah jangkauan penyebaran informasi luas dan dapat dilakukan kapan saja.

Media sosial adalah sebuah platform berbasis digital yang dapat digunakan keperluan pribadi dan organisasi untuk saling berinteraksi satu sama lain. Penggunaan sebagai media promosi dapat dilakukan dengan membuat konten yang berupa gambar, tulisan, video hingga gabungan semuanya. Potensi bisnis yang besar di media sosial harus dimanfaatkan pelaku usaha untuk meningkatkan promosi dengan menggunakan media sosial. Ada beberapa pilihan media sosial yang dapat digunakan dan pilihan media sosial yang digunakan juga harus melihat pengguna atau masyarakat yang menggunakan media sosial. Media sosial yang populer di Indonesia diantaranya YouTube, Facebook, Instagram, WhatsApp, Twitter. Berdasar pada survey yang dikeluarkan Hoot suite (Anonim 2020), pengguna media sosial di Indonesia adalah YouTube $88 \%$ dari jumlah populasi, WhatsApp $84 \%$ dari jumlah populasi, Facebook sebanyak 82\% dari jumlah populasi dan Instagram sebanyak 79\% dari jumlah populasi. Gambar 1 Grafik Media sosial di Indonesia yang populer digunakan.

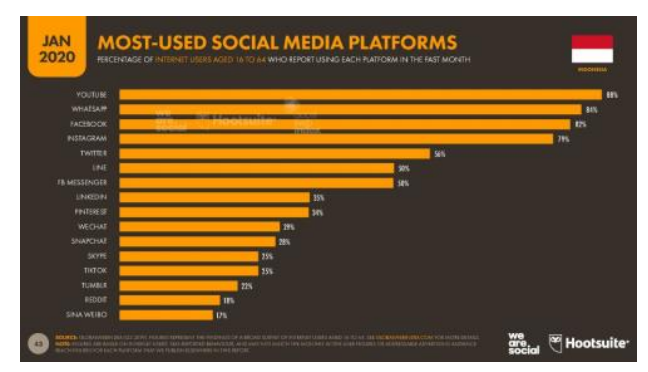

Gambar 1. Grafik Media sosial yang populer di Indonesia

Salah satu media yang banyak digunakan sebagai sarana promosi dan dapat digunakan untuk memasarkan produk dengan berbagai gambar, video dan narasi serta dapat menjangkau masyarakat yang luas adalah Instagram. Instagram adalah platform media sosial yang sangat populer di dunia, terutama di Indonesia.(Helianthusonfri 2020), (Prayogo 2014). Kelebihan Instagram diantaranya Instagram berbasis gambar 
dan video singkat yang cukup efektif dijadikan alat promosi, akun Instagram juga dapat dihubungkan dengan akun Facebook Page . Pengguna Instagram di Indonesia sampai bulan Mei 2020 terutama mengalami peningkatan. Merujuk data dari Napoleon Cat, pada bulan Januari sampai Mei 2020, penggunaan Instagram di Indonesia sebanyak 69,2 juta (Iman 2020). Gambar 2 pertumbuhan pengguna Instagram di Indonesia.

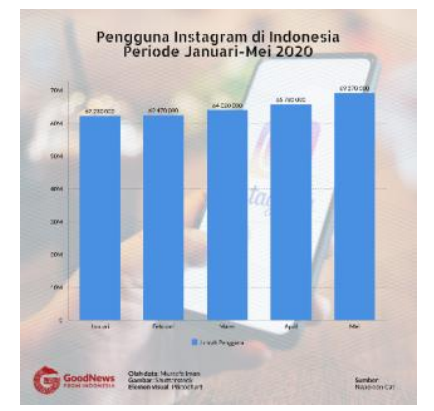

Gambar 2. Pertumbuhan pengguna

Instagram di Indonesia

Mayoritas pengguna Instagram di Indonesia adalah wanita dan usia pengguna paling banyak usia 18-34 tahun. Merujuk pada Napoleon Cat .pengguna yang berusia 18-34 mencapai 25 juta atau sekitar 36-38 \% dan untuk usia 25-34, sebanyak 21 juta. (31-33\%). Gambar 3 dan gambar 4 menunjukkan pengguna berdasar usia dan jenis kelamin. (Iman 2020)

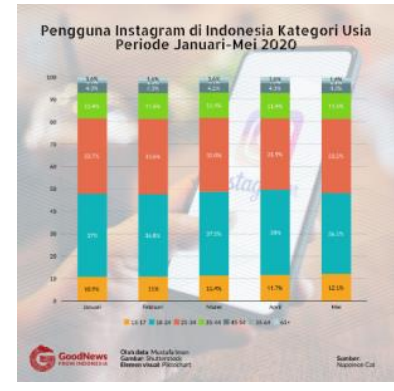

Gambar 3. Pengguna Instagram berdasar Kategori Jenis kelamin

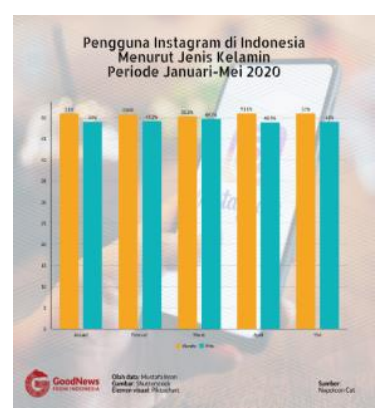

Gambar 4. Pengguna Instagram berdasar Kategori usia

Penelitian yang terkait dengan Instagram dilakukan diantaranya adalah Kurniawan (Kurniawan 2017). Kesimpulan dari penelitian diantaranya Instagram memberikan layanan yang dapat digunakan untuk penyampaian informasi, menyediakan fasilitas yang dapat digunakan untuk melengkapi dan mengisi berbagai informasi, seperti lokasi, usia, aktivitas yang dilakukan dan informasi lain yang sangat dibutuhkan untuk menentukan segmentasi pasar dalam aktivitas marketing. Segmentasi dalam menentukan pasar dapat lebih difokuskan. Di Instagram terdapat fasilitas untuk melakukan penyaringan target atau sasaran pasar dengan agar target dapat atau sesuai sasaran 
berdasarkan informasi yang disajikan serta dapat diakses/ digunakan setiap saat.

Indika (Indika 2017) melakukan penelitian terkait penggunaan Instagram dalam melakukan promosi pada kawasan wisata. Kesimpulan penelitian diantaranya penggunaan Instagram dengan menggunakan foto yang dibuat menarik dengan berbagai kreasi menjadi salah satu faktor yang sangat penting dalam mempromosikan objek wisata sehingga dapat menjadi pilihan atau daya tarik konsumen dalam memilih tempat tujuan wisata. Penggunaan aplikasi Instagram yang menarik dengan berbagai foto atau gambar terbukti punya korelasi kuat dalam memengaruhi minat beli konsumen.

Utari (Untari and Fajariana 2018) melakukan penelitian pada akun Instagram dengan @Subur_Batik. Ha terpenting dalam pengelolaan Instagram adalah kualitas yang tinggi dari konten yang diunggah. Foto dan video dapat memberikan kepada pengguna Instagram informasi menarik. Dengan memaksimalkan konten berupa foto dari produk pelaku usaha Subur Batik yang juga dilengkapi narasi atau tulisan menjadi salah satu faktor yang mendorong keterlibatan pelanggan dalam Instagram.. Akun
@CREMATOLOGY yang menawarkan coffee shop menurut Tampubolon (Tampubolon, Putri, and Atnan 2016) dapat berjalan secara efektif. Beberapa faktor yang membuat Instagram mampu menjadi sarana promosi yang efektif adalah Instagram dapat menjadi media promosi yang murah. Instagram juga efektif karena dapat menjangkau audiensi yang sangat luas. Dengan menggunakan Instagram, penggunanya juga dapat melakukan kegiatan share, sehingga berita maupun informasi yang akan disebar dapat tersebar secara luas. Disamping itu Instagram dapat dianggap sebagai solusi dalam melakukan promosi dengan cara menghemat waktu serta energi dalam membuat promosi.

Promosi yang dilakukan di Screamous Clothing menunjukkan hasil yang positif. Menurut Andriansyah (Andriansyah and Karsa 2018) penggunaan Instagram di Screamous Clothing digunakan sebagai media periklanan, promosi penjualan yang memberikan informasi kepada para pelanggan terutama promo yang ada di Screamous Clothing. Promosi yang ditawarkan seperti, pemberian diskon, pembelian 1 dapat 1 (buy 1 get 1 ).

Disamping penelitian yang mengupas Instagram sebagai media promosi, kegiatan lain yang harus 
dilakukan adalah kegiatan sosialisasi atau pelatihan kepada masyarakat terutama penggunaan media sosial secara benar. Kegiatan pelatihan diantaranya dilakukan oleh (Febrilia, Nasution, and Handarini 2017), (Sudaryanto et al. 2019), (Nilma, Nuzulah, and Mardika 2020), (Andriansyah and Karsa 2018)

\section{METODE DAN PELAKSANAAN}

\section{Metode}

Metode yang digunakan dalam kegiatan ini diawali dengan pemberian kuesioner mengenai penggunaan media sosial dalam melakukan promosi. Hasil kuesioner dilakukan evaluasi untuk ditindak lanjuti dengan pelatihan lain yang lebih spesifik. Pendampingan diberikan dengan fokus pada penggunaan Instagram sebagai media promosi.

\section{Pelaksanaan Kegiatan}

Pelaksanaan kegiatan pengabdian pada masyarakat yang dilaksanakan di Kecamatan Kasihan pada tanggal 10 September 2020. Kegiatan ini merupakan rangkaian kegiatan riset kerja sama antara Deputi Bidang Penguatan Riset dan Pengembangan - Kementerian Riset dan Teknologi/ Badan Riset dan Inovasi Nasional dengan Institut Sains \& Teknologi AKPRIND Yogyakarta.
Kegiatan diikuti oleh perwakilan pelaku usaha yang ada di kecamatan Kasihan.

\section{HASIL DAN PEMBAHASAN \\ Evaluasi Hasil Kuesioner}

Proses sosialisasi diawali dengan pemberian kuesioner pada perwakilan pelaku UKM yang ada di Kecamatan Kasihan. Beberapa pertanyaan dan hasil kuesioner diantaranya

1. Apakah sudah menggunakan media sosial sebagai sarana promosi

Hasil kuesioner pada pertanyaan ini, 100\% responden menjawab sudah menggunakan media sosial sebagai sarana untuk melakukan promosi.

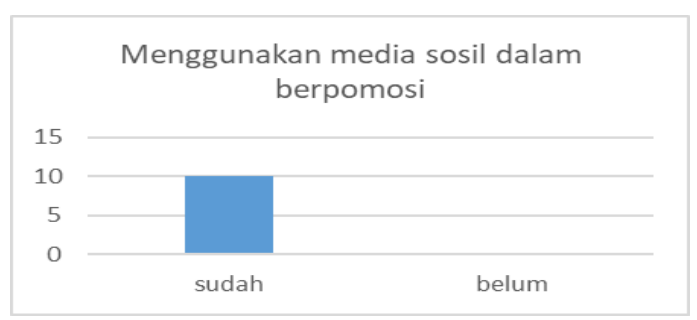

Gambar 5. Hasil responden pertanyaan menggunakan media sosial

2. Peralatan media sosial yang digunakan dalam melakukan promosi Hasil kuesioner pada pertanyaan ini, 100\% responden menjawab menggunakan smartphone 10 responden, menggunakan komputer 4 dan menggunakan kedua piranti tersebut 2 responden. 


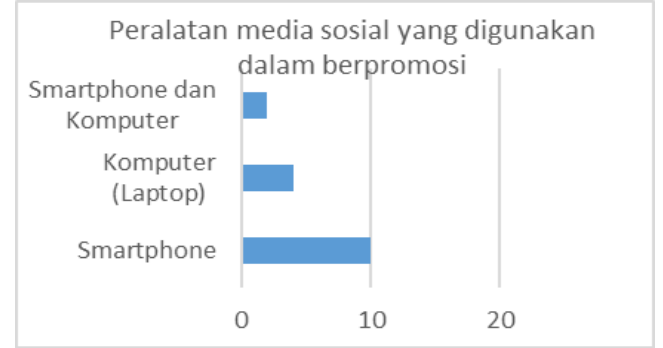

Gambar 6. Hasil responden pertanyaan Peralatan media sosial yang digunakan dalam melakukan promosi

3. Media sosial yang digunakan dalam melakukan promosi

Hasil kuesioner pada pertanyaan ini, 100\% responden menjawab menggunakan 10, menggunakan Instagram 3 dan Facebook.

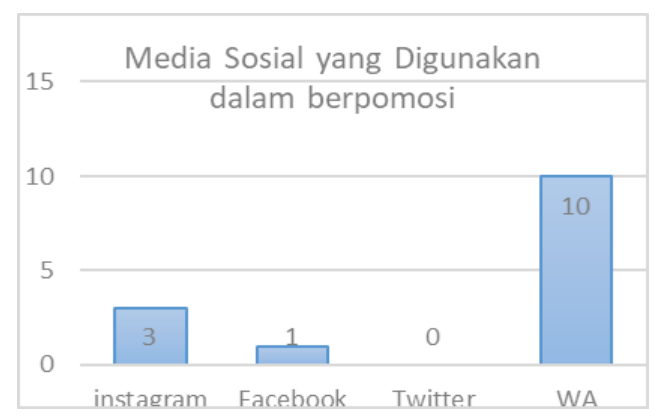

Gambar 7 .Hasil responden pertanyaan

Media Sosial yang Digunakan dalam melakukan promosi

4. Frekuensi Penggunaan Media sosial untuk media promosi

Hasil kuesioner pada pertanyaan ini, penggunaan media sosial sudah sering dilakukan (7 responden) dan 3 responden menjawab kadang-kadang.

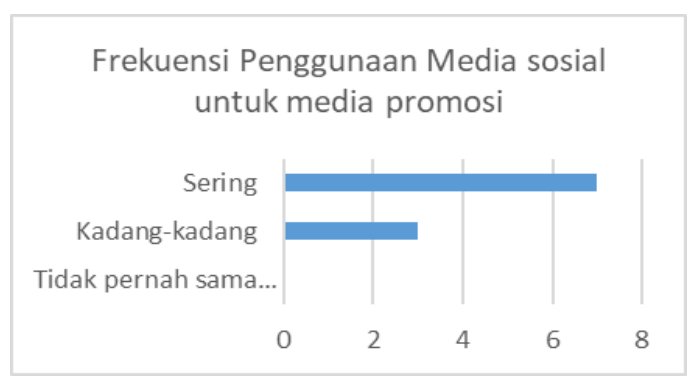

Gambar 8. Hasil responden pertanyaan

Frekuensi Penggunaan Media sosial untuk media promosi

Berdasar hasil kuesioner tersebut, semua peserta sudah menggunakan media sosial an mayoritas menggunakan WhatsApp sebagai media promosi dan belum secara maksimal menggunakan media sosial berjejaring seperti Instagram, Facebook atau Twitter.

\section{Pengenalan Instagram sebagai Media Promosi}

Instagram saat ini menjadi salah satu media sosial yang banyak pengguna. Banyak fitur atau fasilitas yang dapat digunakan dalam melakukan promosi. Salah satu fitur yang ada adalah fitur followers. Fitur ini berguna untuk menjadi pengikut dalam akun Instagram. Fitur ini merupakan salah satu fitur yang sangat populer bagi pengguna Instagram. Semakin banyak followers atau pengikut di akun, maka semakin terkenal dan populer juga akun di media sosial. Fitur lain yang dapat digunakan dalam mempromosikan produk adalah fitur yang dapat digunakan untuk mengunggah atau memasang foto. Fitur 
ini dapat digunakan para pelaku usaha untuk membagikan foto-foto produk dan komentar atau narasi dari keunggulan produk. Gambar 9 merupakan contoh dari laman Instagram @konvekskuy yang digunakan dalam melakukan promosi. Gambar 10, foto dan narasi yang disampaikan dalam memosting produk ukm

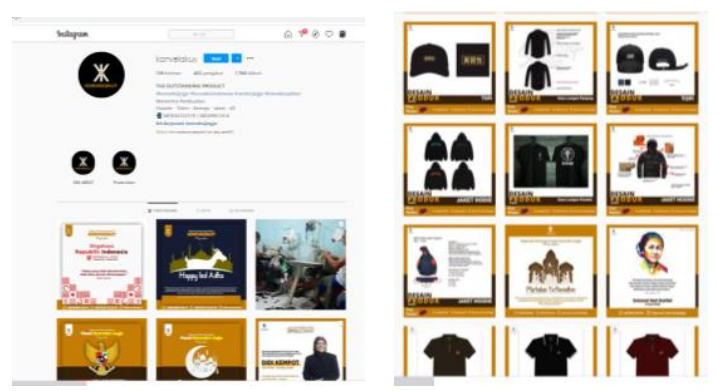

Gambar 9. Laman

www.instagram.com/konvekskuy/
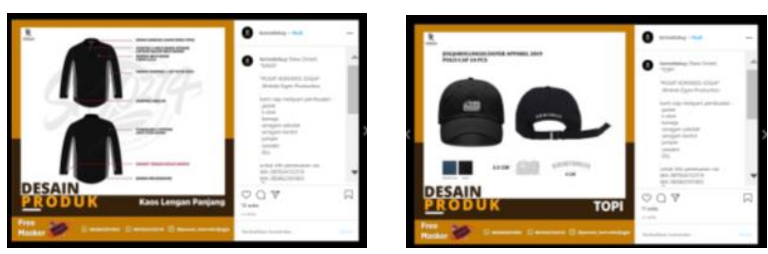

Gambar 10. Model promosi berbasis

gambar dan narasi di

www.instagram.com/konvekskuy/

\section{Pelaksanaan sosialisasi}

Pelaksanaan kegiatan ini merupakan tindak lanjut dari kegiatan riset yang bertujuan untuk meningkatkan promosi pelaku ULM dengan mengoptimalkan internet baik sebagai media promosi maupun marketplace. Pelaksanaan riset dan pengabdian pada masyarakat ini juga bekerja sama dengan Dinas Komunikasi dan Informatika kabupaten Bantul serta kecamatan Kasihan. Proses pelaksanaan sosialisasi ada pada gambar 11 .
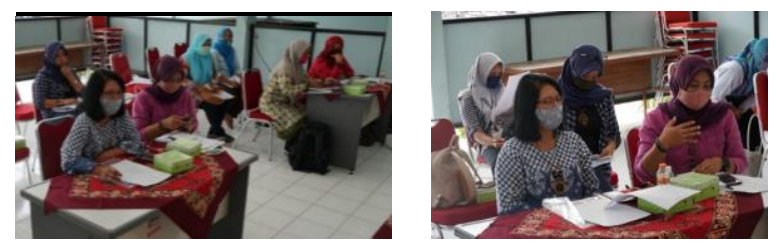

Gambar 11. Peserta pendampingan media sosial

Sebagai upaya untuk memberikan gambaran penggunaan Instagram, dalam kegiatan ini juga disampaikan paparan dari pengguna usaha yang sudah menggunakan Instagram. Gambar 12 merupakan pemaparan materi yang disampaikan oleh pelaku usaha yang menggunakan Instagram sebagai media promosi
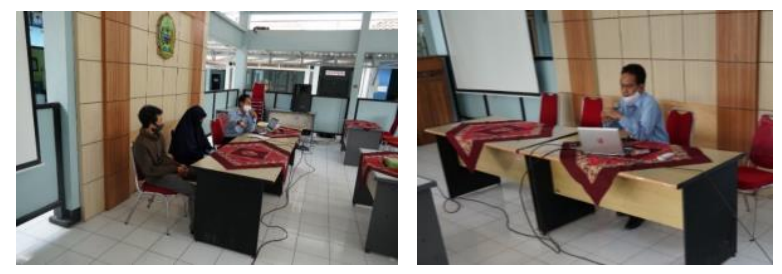

Gambar 12. Pemaparan materi oleh TIM IST AKPRIND

\section{PENUTUP}

\section{Simpulan}

Media sosial dapat digunakan pelaku usaha sebagai salah satu untuk memperkenalkan produk yang dihasilkan. Keberlanjutan dari penggunaan media sosial ini haris selalu dilakukan dan pembaharuan foto produk 
harus sering dilakukan sehingga pengguna dapat memperoleh informasi yang diinginkan. Penggunaan media sosial tidak hanya sebatas menggunakan Instagram tetapi juga dapat menggunakan media sosial yang lain. Faktor lain yang haris diperhatikan adalah sasaran produk dipasarkan pada segmen yang tepat dan menggunakan hastag menjadi salah satu faktor dalam menggunakan media sosial.

\section{UCAPAN TERIMAKASIH}

Ucapan terima kasih kepada Deputi Bidang Penguatan Riset dan Pengembangan - Kementerian Riset dan Teknologi/ Badan Riset dan Inovasi Nasional yang telah memberi dukungan dana untuk kegiatan penelitian pada skema penelitian terapan unggulan perguruan tinggi tahun pendanaan 2019 dan 2020 dan Dinas Komunikasi dan Informatika kabupaten Bantul yang telah memberikan kesempatan kepada tim IST AKPRIND untuk memberikan pendampingan serta Kecamatan Kasihan yang telah memberikan fasilitas dalam kegiatan pendampingan ini.

\section{DAFTAR PUSTAKA}

Andriansyah, Tubagus and Satya Indra Karsa. 2018. "Pemanfaatan Media Sosial Instagram Sebagai Sarana
Promosi Screamous Clothing." Pp. 88-93 in Prosiding Manajemen Komunikasi.

Anonim. 2020. Digital 2020 Indonesia.

Febrilia, Ika, Hafifah Nasution, and Dwi

Handarini. 2017. "Pelatihan

Penggunaan Jejaring Sosial

Instagram Dalam Memasarkan

Barang Pada Ibu-Ibu Pkk Di

Kelurahan Rawamangun Jakarta

Timur." Sarwahita 14(02):108-13.

Helianthusonfri, Jefferly. 2020.

Instagram Marketing Untuk

Pemula. Jakarta: PT Elex Media

Komputindo.

Iman, Mustafa. 2020. "Pengguna Instagram Di Indonesia Didominasi Wanita Dan Generasi Milenial."

Retrieved September 12, 2020 (https://www.goodnewsfromindones ia.id/2020/06/14/penggunainstagram-di-indonesia-didominasiwanita-dan-generasi-milenial).

Indika, Deru R. 2017. "MEDIA SOSIAL INSTAGRAM SEBAGAI SARANA PROMOSI UNTUK

MENINGKATKAN MINAT BELI KONSUMEN.” Jurnal Bisnis Terapan 01(01):25-32.

Kurniawan, Puguh. 2017.

"PEMANFAATAN MEDIA SOSIAL INSTAGRAM SEBAGAI KOMUNIKASI PEMASARAN 
MODERN PADA BATIK BURNEH

Puguh Kurniawan Universitas

Trunojoyo Madura." Kompetensi 11(2):217-25.

Nilma, Rahnita Nuzulah, and Putri Dina Mardika. 2020. "PENYULUHAN TENTANG KEWIRAUSAHAAN MELALUI MEDIA SOSIAL KEPADA IBU-IBU PKK DI WILAYAH.” Jurnal PKM: Pengabdian Kepada Masyarakat 03(01):101-6.

Prayogo, Dewa Eka. 2014. 30 Hari Jago Jualan. Sukabumi: Delta Saputra.

Sudaryanto, Haruno Sajati, Anggraini Kusumaningrum, Dwi Nugraheny, Salam Aryanto, and Hero Wintolo. 2019. "Pendampingan Pemasaran Produk Menggunakan Instagram Bagi Pelaku Usaha Mikro Kecil
Menengah (UMKM) Di Kecamatan Pathuk Gunung Kidul.” KACANEGARA Jurnal Pengabdian Pada Masyarakat 3(1):61-68.

Tampubolon, Mikharisti, Yuliani Rachma Putri, and Nur Atnan. 2016. "Strategi Promosi Coffee Shop Melalui Media Sosial Instagram (Studi Deskriptif Pada Akun @crematology).” EProceeding of Management 3(2):2421-32.

Untari, Dewi and Dewi Endah Fajariana. 2018. "Strategi Pemasaran Melalui Media Sosial Instagram (Studi Deskriptif Pada Akun @Subur_Batik).” Widya Cipta Jurnal Sekretari Dan Manajemen 2(2):271-78. 